\section{A rare case of WAGR syndrome with Peter anomaly}

\author{
Rohit S. Adyanthaya, Michael X. Repka \\ Wilmer Ophthalmological Institute, the \\ Johns Hopkins University School of \\ Medicine, Baltimore, Maryland, USA
}

\section{Abstract}

We report a case of the WAGR syndrome associated with the Peter anomaly. A 6-day-old baby boy was found to have bilateral corneal opacities, 360 degrees of iris hypoplasia and cataracts. Physical examination revealed bilateral undescended testicles. Family history was unremarkable and genetic testing revealed a deletion 11p11.2-13 indicating WAGR syndrome. A Wilms tumor developed and was removed at age 2 years. There was moderate developmental delay. The occurrence of WAGR syndrome with Peter anomaly has been reported in three other patients to our knowledge.

\section{Introduction}

WAGR syndrome is a disorder characterized by microdeletions of the short arm of chromosome 11 at band p13 and is clinically associated with Wilms tumor, aniridia, genitourinary anomalies and mental retardation (W-A-G-R). Deletions of neighboring genes, the PAX6 ocular development gene and the Wilms tumor gene (WT1), result in aniridia and Wilms tumor, respectively. Peter anomaly is an anterior segment dysgenesis in which there is abnormal development of the anterior chamber.

\section{Case Report}

A 6-day-old infant boy was evaluated for bilateral corneal opacities. His prenatal history was uneventful with spontaneous vaginal delivery at 36 weeks gestation. The right eye had a central white corneal opacity, which extended to the limbus from 4 o'clock to 7 o'clock. There were 360 degrees of iris hypoplasia with iris vessels visible. There was an area of iridocorneal adhesion inferiorly. The anterior chamber was shallow. The horizontal and vertical corneal diameters were $8.8 \mathrm{~mm}$. There was a nuclear cataract visible behind the corneal opacification. The left eye had denser central corneal opacification. There were 360 degrees of iris hypoplasia with a vascular ring at the poorly formed pupillary margin. The anterior chamber was noted to be shallow, especially inferiorly with an area of irido-corneal adhesions. A dense nuclear and cortical cataract was noted. The corneal diameters were $9.0 \mathrm{~mm}$ vertical and $10.5 \mathrm{~mm}$ horizontal. The intraocular pressure measured with a handheld applanation tonometer (Tono-pen: Bio-Rad, Santa Ana, CA, USA) varied from 18 to $22 \mathrm{~mm}$ of $\mathrm{Hg}$ in both eyes. B-scan ocular echography found bilateral lenticular opacities and attached retinas. Systemic examination revealed bilateral undescended testicles. Abdominal sonography showed normal kidneys. Family history was unremarkable. Genetic testing revealed a deletion on chromosome 11p11.2-13. Bilateral (non-simultaneous) penetrating keratoplasties with lensectomy were performed. A second corneal graft was performed in each eye after about one year. Glaucoma developed in the right eye, with subsequent retinal detachment, and corneal graft failure. The graft in the left eye remained clear at 6 years of age. In addition, quarterly sonograms of the abdomen were conducted. A computed tomography (CT) scan of the abdomen and pelvis at age 2 years demonstrated a $2.0 \times 1.8 \times 2.4 \mathrm{~cm}$ mass in the mid pole of the left kidney leading to the diagnosis of Wilms tumor, which was successfully excised.

The pathology was consistent with a stage I Wilms tumor, and was negative for tumor-specific loss of heterozygosity. Furthermore, over time, he was noted to have moderate developmental delay with learning disability and attention deficit hyperactivity disorder (ADHD).

\section{Discussion}

The occurrence of WAGR syndrome with Peter anomaly has been reported in three other patients to our knowledge. These were a 2-month-old boy with the Peter anomaly and deletion of 11p13 who did not have Wilms tumor, ${ }^{1}$ a 6 -day-old boy with the Peter anomaly and a Wilms tumor (chromosomal analysis was not performed $)^{2}$ and a 1-month-old boy with deletion on chromosome 11p13-15.1 with an anomalous anterior segment and microphthalmos with bilateral Wilms tumors developing at the age of 3 years. ${ }^{3} \quad$ Our case of Peters anomaly plus Wilms tumor presents further evidence of an association of WAGR syndrome and Peter anomaly.

WAGR syndrome (OMIM 194072) was first described by Miller, et al. ${ }^{4}$ and is an extensively studied contiguous gene syndrome. Children with WAGR syndrome invariably have a germline chromosomal deletion at 11p of variable size, but always affecting WT1 and PAX6 genes, both on band 13 (11p13). ${ }^{5}$

Aniridia occurs sporadically or as an autosomal dominant inherited condition. One-third
Correspondence: Rohit Adyanthaya, Stony Brook University, HSC L-2, Rm 152, Stony Brook, New York 11768, USA.

E-mail: rohiteyedoctor@gmail.com

Key words: WAGR syndrome, Peter anomaly.

Received for publication: 9 April 2011.

Accepted for publication: 31 July 2011.

This work is licensed under a Creative Commons Attribution NonCommercial 3.0 License (CC BYNC 3.0).

CC Copyright R.S. Adyanthaya and M.X. Repka., 2011 Licensee PAGEPress, Italy

Eye Reports 2011; 1:e4

doi:10.4081/eye.2011.e4

of patients with sporadic aniridia will be found to have WAGR syndrome. ${ }^{6}$ The PAX6 gene, involved in ocular embryogenesis, has been identified as a candidate gene for aniridia. Therefore, it is reasonable that ocular anomalies other than aniridia might result from a deletion in the PAX6 gene.

The second gene in this region is the WT1 gene (Wilms tumor gene). Individuals who have a deletion in this gene have an increased risk for developing Wilms tumor as well as having abnormal genitalia. Their risk of having Wilms tumor is around $45-57 \%{ }^{7,8} 90 \%$ of Wilms tumors present by the age of 4 years and $98 \%$ by the age of 7 years. Screening for Wilms tumor includes ultrasound every three months during this period. There is also approximately a $40 \%$ chance of renal problems, including renal failure in late adolescence in children with WAGR and Wilms tumor. ${ }^{9}$ The associated genitourinary findings include cryptorchidism present in nearly $60 \%$ of the cases,${ }^{8}$ hypospadias, micropenis and other urinary tract abnormalities (also caused by WT1 gene deletions).

Peter anomaly is an anterior segment dysgenesis in which abnormal cleavage of the anterior chamber occurs. Mutations may involve the PAX6 gene..$^{910}$ with reported cases of Peter anomaly and aniridia. ${ }^{11,12}$ though Churchill, et $a l$. found no such association. ${ }^{13}$ Peter plus syndrome is characterized by genitourinary abnormalities, syndactyly, brachycephaly, and cardiac, neural, and hearing abnormalities. Since the PAX6 gene is also involved in the development of the central nervous system, a wide variety of neurological, behavioral, and psychiatric abnormalities can also be present. ${ }^{8}$

\section{References}

1. Hanson IM, Fletcher JM, Jordan T, et al. Mutations at the PAX6 locus are found in 
heterogeneous anterior segment malformations including Peters' anomaly. Nat Genet 1994;6:168-73.

2. Eiferman RA. Association of Wilms' tumor with Peters' anomaly. Ann Ophthalmol 1984;16:933-4.

3. Kawase E, Tanaka K, Honna T, Azuma N. A case of atypical WAGR syndrome with anterior segment anomaly and microphthalmos. Arch Ophthalmol 2001;119:18556.

4. Miller RW, Fraumeni JF Jr, Manning MD. Association of Wilms tumor with aniridia, hemihypertophy and other congenital malformations. N Engl J Med 1964;270:922-7.

5. Crolla JA, Cawdery JE, Oley CA, et al. A FISH approach to defining the extent and possible clinical significance of deletions at the WAGR locus. J Med Genet 1997;34:
207-12.

6. Ivanov I, Shuper A, Shohad M, et al. Aniridia: recent achievements in clinical practice. Eur J Pediatr 1995;154:795-800.

7. Muto R, Yamamori S, Ohashi H, Osawa M. Prediction by FISH analysis of the occurrence of Wilms tumor in aniridia patients. Am J Med Genet 2002;108:285-9.

8. Fischbach BV, Trout KL, Lewis J, et al. WAGR syndrome: a clinical review of 54 cases. Pediatrics 2005;116:984-8.

9. Breslow NE, Collins AJ, Ritchey ML, et al. End stage renal disease in patients with Wilms tumor: results from the National Wilms Tumor Study Group and the United States Renal Data System. J Urol 2005; 174:1972-5.

9. Azuma N, Yamaguchi Y, Handa H, et al. Missense mutation in the alternative splice region of the PAX6 gene in eye anomalies. Am J Hum Genet 1999;65:65663.

10. Sawada M, Sato M, Hikoya A, et al. A case of aniridia with unilateral Peters anomaly. J AAPOS 2011;15:104-6.

11. Mayer UM. Peters' anomaly and combination with other malformations (series of 16 patients). Ophthalmic Paediatr Genet 1992;13:131-5.

12. Koster R, van Balen AT. Congenital corneal opacity (Peters' anomaly) combined with buphthalmos and aniridia. Ophthalmic Paediatr Genet 1985;6:241-6.

13. Churchill AJ, Booth AP, Anwar R, Markham AF. PAX 6 is normal in most cases of Peters' anomaly. Eye (Lond) 1998;12:299303. 